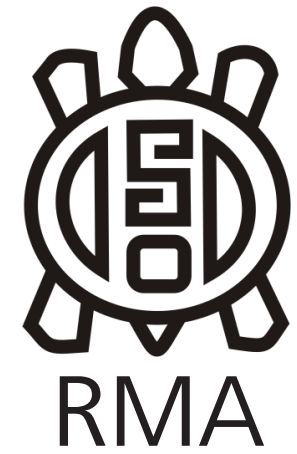

Dossier

\title{
Materias primas en la Región Pampeana bonaerense: panorama actual y convocatoria a un trabajo colectivo
}

\author{
Lithic raw material in the Pampean region of the Buenos Aires province: \\ current situation and call for a collective work
}

Selene Arislur", Franco Pazzi ${ }^{* *}$, Natalia Mazzia** Nora Flegenheimer ${ }^{* *}$

"CONICET-Universidad Nacional del Centro de la Provincia de Buenos Aires, Instituto de Geografía, Historia y Ciencias Sociales. E-mail: arislurselene@gmail.com

"CONICET, Área Arqueología y Antropología, Museo de Ciencias Naturales, Municipalidad de Necochea, Argentina. E-mail: francopazzi@hotmail.com; natymazzia@yahoo.com.ar; norafleg@gmail.com

\begin{abstract}
Resumen
Las investigaciones sobre fuentes de materias primas líticas fueron uno de los motores que impulsaron a la arqueología pampeana. La identificación de áreas de aprovisionamiento en la región cuenta con una trayectoria que comenzó en la década de 1990 y se extiende hasta la actualidad. La información disponible fue generada por diversos equipos, asentados en distintos espacios institucionales, que han abordado la temática con metodologías y perspectivas teóricas diferentes. Como resultado, existe un importante pero heterogéneo cúmulo de información, en lo que respecta a variables, escalas, unidades y categorías utilizadas, publicado de manera dispersa.

En este trabajo realizamos una revisión bibliográfica sobre los estudios de fuentes de materias primas líticas en la Región Pampeana bonaerense (Argentina). Nuestro objetivo es sintetizar y sistematizar la información publicada para luego proponer la creación de una base digital abierta que reúna los resultados disponibles. Esto requiere una puesta en común y un consenso entre quienes trabajamos en la temática para aunar esfuerzos en una construcción colectiva que sea útil a toda la comunidad académica.
\end{abstract}

Palabras clave: Materias primas líticas; Fuentes de aprovisionamiento; Reservorio digital; Revisión bibliográfica; Propuesta de trabajo.

\begin{abstract}
Lithic raw material studies were a key impulse to Pampean archaeology. The identification of lithic procurement areas goes back to the 1990's and continues today. Different research teams, working for different institutions, have produced important information on this subject. Also, diverse methodologies and theoretical perspectives were applied to these studies. As a consequence, there is an important, but heterogeneus, body of knowledge published dispersed way.

In this paper we present a review of the literature on lithic raw material sources in Buenos Aires province in the Pampean Region (Argentina). Our main goal is to synthesize and systematize the published information, in order to lay foundations for the creation of an open digital data base to bring together such information. Finally, we consider that a previous general discussion and agreement on certain issues are necessary when creating a collective construction useful for the whole academic community.
\end{abstract}

Keywords: Lithic raw materials; Procurement areas; Digital database; Academic literature review; Open call.

\section{Introducción}

Los trabajos de identificación de fuentes de materias primas líticas se han desarrollado en Argentina de forma casi ininterrumpida desde la década de 1980 (por ejemplo, Bellelli, 1988; Nami, 1992; Oliva y Barrientos, 1988), impulsados por el marco teórico procesual (Bamforth, 1992; Binford, 1962; Flegenheimer y Bellelli, 2007, entre otros). Al estar a cargo de diferentes equipos de investigación, los datos primarios se encuentran dispersos en distintos espacios de trabajo e incluyen: información litológica de las materias primas (descripciones micro 
y macroscópicas), distribución de los recursos (fuentes potenciales y canteras primarias, secundarias y/o terciarias), características mecánicas de las rocas, sus aptitudes para la talla y, en algunos casos, la conformación de litotecas. La mayor parte de esta información se encuentra publicada en revistas académicas y algunas de estas investigaciones también han sido proyectadas en entornos de Sistemas de Información Geográfica.

En la región pampeana bonaerense las fuentes de materias primas han sido estudiadas intensamente. Esto se vio favorecido porque los afloramientos rocosos están acotados espacialmente, facilitando su ubicación y posterior análisis (Bayón y Flegenheimer, 2004; Bayón et al., 1999). Actualmente, se distinguen cuatro grandes sectores con fuentes en la región: los sistemas serranos Tandilia y Ventania, con las fuentes más utilizadas regionalmente; el área interserrana y el litoral marítimo (Figura 1). Estas áreas presentan diferencias en cuanto a las rocas, sus características petrográficas, abundancia, distribución y forma de presentación (Barros y Messineo, 2004; Bayón y Zavala, 1997; Bonomo, 2004; Catella, 2014; Catella et al., 2010; Colombo, 2013; Flegenheimer et al., 1996; Madrid y Salemme, 1991; Matarrese, 2015; Messineo, 2008; Oliva y Barrientos, 1988; Ormazabal, 1999; Vecchi, 2010a, entre otros). Las investigaciones sobre las fuentes de rocas en la región actuaron como punto de partida para estudios sobre movilidad, modalidades de extracción y acceso a los recursos, territorialidad y contactos entre los grupos, no solo pampeanos sino también de regiones vecinas (Barros et al., 2015; Bayón et al., 1999, 2006; Catella, 2014; Colombo, 2013; Flegenheimer y Bayón, 2002; Heider, 2016; Mazzanti, 2006; Messineo y Barros, 2015, entre otros).

En virtud de la cantidad de investigaciones acerca de las materias primas y la abundante información, el objetivo de este trabajo es convocar a la construcción colectiva de una base de datos digital de recursos líticos en la región pampeana bonaerense, que resulte, además, un aporte a la conformación de una base de mayor escala en todo el país. Para ello, realizamos una revisión bibliográfica de los principales trabajos que incluyen estudios sobre fuentes de recursos líticos en la provincia de Buenos Aires y sintetizamos parte de la información disponible en la actualidad para crear un estado del arte de las investigaciones, con el fin de visibilizar el cúmulo de datos publicados y sus características. Asimismo, reflexionamos sobre disidencias de nomenclaturas que surgieron y la importancia del trabajo colectivo.

\section{Hacia la creación de un repositorio digital de fuentes de materias primas líticas}

Según Borrel et al., (2015), la curaduría digital es la creación, gestión, almacenamiento, preservación y exposición efectiva de información digital a un conjunto

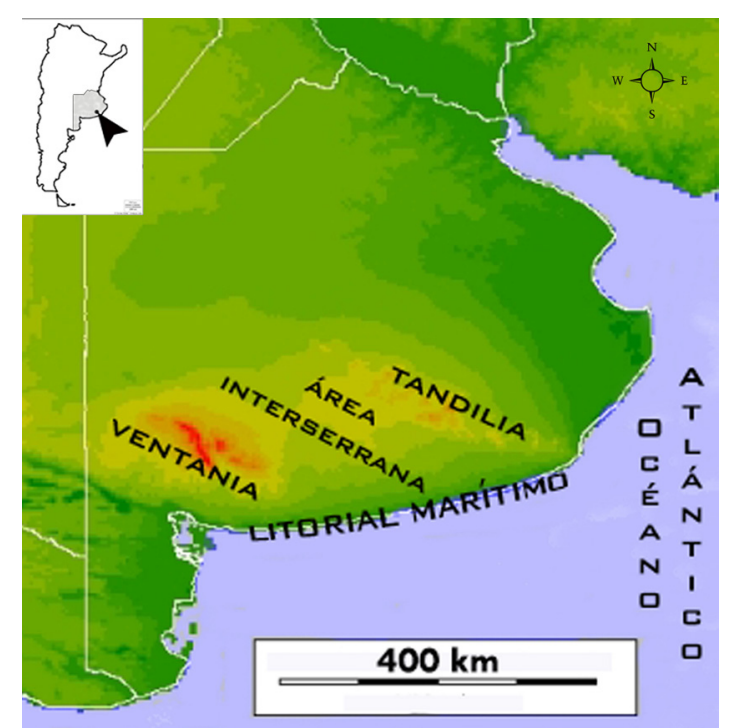

Figura 1. Mapa de la Región Pampeana bonaerense indicando los cuatro sectores con fuentes de aprovisionamiento lítico.

Figure 1. Map of the province of Buenos Aires in the Pampean Region indicating the four areas with lithic raw material sources.

de usuarios. Resulta un nuevo campo de aplicación de conocimientos donde confluyen productores de datos y trabajadores de la información (Lee y Tibbo, 2007). Para que se materialice la base de datos es necesario contar con participantes capacitados en informática, apoyo financiero para solventar el armado y mantenimiento de la plataforma digital, cursos de capacitación, entre otras cosas. Por ello, este proyecto significa un desafío al interior de la arqueología en Argentina, dada la escasa formación profesional que tenemos en materia de preservación digital. En este sentido, consideramos que un proyecto colaborativo permitiría optimizar recursos y tiempo, compartiendo de manera más eficiente la información, a la par que se discutirían estándares y criterios para construir los principios metodológicos comunes para la recolección de datos (Cantamutto y Delfa, 2015).

Desde hace varios años, en el ámbito científico argentino se promueven debates en torno al uso y creación de fuentes de datos digitales de acceso abierto. Uno de los argumentos a favor de estos repositorios es que los mismos permitirían comenzar un proceso de democratización de la ciencia. Sin embargo, coincidimos con Izeta y Cattáneo (2018) en que la efectividad de este proceso depende del acceso simbólico y material a la tecnología que se distribuye de manera desigual en la Argentina.

En ese contexto, en 2011 CONICET inició el proyecto PLIICS (Plataforma Interactiva de Información en Ciencias Sociales), cuyo propósito es ofrecer "a la comunidad académica un panorama integral y acceso eficiente a los datos primarios disponibles en Ciencias Sociales en 
el CONICET" (Pluss y Leff, 2013, p-175). Con un objetivo similar, se diseñó el Sistema Nacional de Repositorios Digitales del entonces Ministerio de Ciencia, Tecnología e Innovación Productiva (MINCyT), una red interoperable de repositorios digitales en ciencia y tecnología. En la actualidad, la iniciativa depende de la Secretaría de Gobierno de Ciencia, Tecnología e Innovación Productiva del Ministerio de Educación, Cultura, Ciencia y Tecnología y del Consejo Interinstitucional de Ciencia y Tecnología (CICyT). También, en 2015 se creó el Programa de Digitalización y Acceso Abierto de Colecciones en las Ciencias Sociales y Humanidades, en el ámbito de la Secretaría de Articulación Científico Tecnológica del ex MINCyT. Sin embargo, los esfuerzos por la digitalización y preservación de los conocimientos científicos y populares muchas veces responden a iniciativas institucionales de menor escala como universidades, museos, archivos históricos, bibliotecas y grupos de investigación (Izeta y Cattáneo, 2018).

Dentro de la diversidad de repositorios digitales, las bases de datos sobre tecnología lítica y litotecas cuentan con un gran impulso a nivel internacional, principalmente a partir de la primera década del siglo XXI. Diferentes países cuentan con litotecas digitales: por ejemplo, EEUU, Irlanda, Australia, Polonia, España, Canadá y Rumania (Anderson y Horgen, 2013; Crandell, 2009; Ditchfield y Ward, 2019; Driscoll et al., 2016; Ortega et al., 2017; Sánchez de La Torre et al., 2014; Soto et al., 2017; Theriault, 2013; Werra et al., 2017). Estas bases de datos buscan resolver la dificultad de comparar estudios líticos en áreas distintas o producidas por investigadores/ as diferentes, a partir de la unificación de criterios para describir los materiales líticos y para presentar las fuentes de rocas, creando así, un lenguaje común entre grupos de investigación, favoreciendo la comunicación y puesta en común de los datos (Alberti y Fernández, 2015). Los repositorios líticos no sólo facilitan la comparación entre rocas diferentes (Crandell, 2009; Dietchfield y Ward, 2019; Theriault, 2013), sino también entre aquellas con variabilidad litológica interna, como, por ejemplo, los sílices o chert (Sánchez de La Torre et al., 2014; Soto et al., 2017; Ortega et al., 2017).

Resaltamos que todas estas bases internacionales registran y presentan de manera muy detallada las caracterizaciones litológicas de cada materia prima, así como la localización espacial de las fuentes con el apoyo de mapas regionales georeferenciados. Asimismo, casi todas las litotecas cuentan con imágenes y muestras de mano que facilitan las identificaciones macroscópicas. En Argentina, existen antecedentes de síntesis sobre fuentes líticas a escala regional, así como también, propuestas clasificatorias unificadoras para la descripción macroscópica de materiales líticos (por ejemplo, Alberti y Fernández, 2015; Berón, 2006; Escola, 2003; Fernández y Alberti, 2013). Estos trabajos reflejan disidencias teóricometodológicas y de clasificación que también atraviesan las investigaciones en nuestra zona de análisis.

\section{Metodología}

Las construcciones de bases de datos digitales implican la planificación de distintas etapas de trabajo. En este sentido, la PLIICS de CONICET cuenta con una red interdisciplinaria de investigadores, bibliotecarios, informáticos y archivistas de cinco institutos de Ciencias Sociales con un mismo plan de trabajo divido en etapas, metas y lapsos temporales establecidos. El objetivo de la red es construir experiencias de creación de colecciones de datos y organizar una plataforma de conocimiento en común sobre datos científicos (Pluss y Leff, 2016).

A una escala menor, Borrel et al., (2015) proponen una metodología de relevamiento para la planificación de proyectos de curaduría de datos y preservación digital en el Instituto de Investigaciones en Humanidades y Ciencias Sociales de la Universidad Nacional de La Plata (IdIHCS-FaHCE-UNLP/CONICET). Esta incluye cinco etapas de trabajo: 1-la identificación de las líneas de trabajo desarrolladas; 2- la identificación de las personas o grupos que trabajen cada línea; 3- la definición de la política que regirá el sistema o la plataforma digital (en concordancia con la normativa vigente y explicitando cuestiones éticas, políticas de acceso a la información, propiedad intelectual, quiénes pueden aportar datos y qué características legales deben tener esos datos); 4- la formación de un grupo de trabajo con distintos perfiles profesionales; 5- el relevamiento (identificación y clasificación), que implica generar un corpus de conocimiento sobre los materiales existentes y el formato de origen (papel, audio, archivos digitales, fotografía, video, etc.). Lo importante en este punto es establecer qué tipo de datos existen, quién los produjo, dónde se encuentran y clasificarlos en función de criterios relevantes (Borrel et al., 2015).

El presente trabajo aporta en tres de las cinco etapas de la anterior propuesta metodológica: en la identificación de las instituciones involucradas, de las personas o grupos vinculados a la temática, y principalmente, en el relevamiento de datos. Para ello, revisamos las publicaciones científicas nacionales, tesis de licenciatura y doctorales, que contengan datos inéditos sobre fuentes de materias primas líticas dentro de la provincia de Buenos Aires. Planteamos este recorte espacial con un criterio analítico basado en la simplificación, ya que es un límite fijo que no genera disenso al interior de la comunidad científica. Además, conforme a la Ley Nacional 25.743/03, los permisos de trabajo, bases de datos e informes de investigación responden a entes gubernamentales provinciales. En el caso de la provincia de Buenos Aires, este ente es el Centro de Registro del Patrimonio Arqueológico y Paleontológico (C.Re.P.A.P.). Por estas razones, consideramos que los límites provinciales resultan más operativos para realizar colectivamente esta base de datos digital. 
Como punto de partida para la búsqueda bibliográfica tomamos la Tesis Doctoral de Colombo (2013). Este trabajo, además de ser una síntesis de las publicaciones referidas a fuentes de materias primas en la provincia de Buenos Aires hasta el año 2010, describe nuevas fuentes. Por ello, este trabajo fue analizado como una fuente en sí misma y como una primera base de información bibliográfica para empezar la búsqueda.

Una vez registrados los trabajos allí citados, continuamos con la revisión de las revistas científicas nacionales publicadas desde el año 2010 hasta el 2018. Se trata de Relaciones de la Sociedad Argentina de Antropología, La Zaranda de Ideas, Intersecciones en Antropología, Revista del Museo de Antropología, Revista del Museo de La Plata (sección Antropología), Cuadernos del INAPL, Cuadernos del INAPL Series Especiales y Cazadores-Recolectores del Cono Sur. A su vez, examinamos las Actas publicadas de seis Congresos de Arqueología de la Región Pampeana Argentina (del I al VI) y de los tres Congresos Nacionales de Arqueología Argentina, publicados desde 2010 hasta la fecha. Por último, revisamos siete Tesis Doctorales y una de Licenciatura cuyos temas de investigación se relacionan específicamente con la identificación de fuentes de materias primas líticas en la provincia de Buenos Aires.

Una vez reunida toda la bibliografía, analizamos sistemáticamente cada producción académica. Para ello, conformamos una ficha de registro con los datos que consideramos pertinentes de ser volcados a una futura base de datos digital. Para esta etapa fue clave comprender quiénes originan los datos, quiénes los utilizan actualmente y quiénes lo harán en el futuro (Harvey, 2007). El objetivo fue sistematizar la información de manera tal que permita una comparación final entre trabajos y de esta manera, pensar categorías a incluir o excluir del diseño de la base de datos. También se registró la diversidad de formatos de origen de la información (existencia de mapas, puntos GPS, litotecas, imágenes, entre otros).

Las fichas utilizadas constan de la cita del artículo o tesis con la pertenencia institucional de cada autor/a; los tipos y cantidad de materias primas tratadas; la localización geográfica de la fuente; la presencia de mapas y/o puntos georreferenciados; nombre y tipo del sitio (fuente potencial, cantera primaria, secundaria o terciaria, cantera-taller, etc.); la disponibilidad de la roca (continua, dispersa, concentrada, aislada o restringida, etc.); la abundancia o volumen de la materia prima en cada fuente (abundante, moderada, escasa); la accesibilidad a las mismas (fácil, moderada, difícil); la forma en la que aparece (bloques, filones, nódulos, rodados); el tamaño de los clastos; el color de las rocas; si se hicieron análisis petrográficos y si éstos se acompañan con descripciones geológicas e imágenes de los cortes delgados; la calidad para la talla y los criterios utilizados para su evaluación; la cronología de los sitios y el método utilizado para su estimación; los modos de extracción de las rocas; si se incluyen imágenes de los afloramientos, y si se tomaron muestras de referencias para el armado de litotecas. Por último, en cada ficha se destina un espacio destinado a las observaciones.

\section{Análisis de los datos y resultados}

A partir del relevamiento exhaustivo de todas las publicaciones y presentaciones académicas incluidas en nuestro recorte analítico, encontramos que 37 trabajos científicos exponen fuentes de materias primas líticas en la provincia de Buenos Aires y/o tratan información inédita adicional sobre una fuente publicada previamente (27 registran nuevas fuentes y 10 agregan información) (Tabla 1). Además, constatamos que las publicaciones sobre esta temática en la provincia comenzaron sistemáticamente a partir de la década de 1990, desarrollándose hasta la actualidad, y que incluyen 35 investigadores/as con 22 pertenencias institucionales diferentes.

En total, se identificaron 32 materias primas líticas distintas en la región de estudio (Tabla 1). De estas rocas, 16 fueron utilizadas para formatizar artefactos mediante talla, 17 para hacerlo mediante actividades de picado, abrasión, pulido y uso (P.A.P.U.) y tres sirvieron como pigmentos minerales. Esto implica, entonces, que algunas rocas sirvieron tanto para la talla como para P.A.P.U. Sin embargo, notamos una diferencia significativa en la cantidad de autores/as y publicaciones que se dedicaron al estudio de las rocas para la talla en relación con los que lo hicieron para P.A.P.U. Sólo seis publicaciones, realizadas por 4 investigadores/as, reúnen las 17 variedades utilizadas para picado, abradido, pulido y uso en la región bonaerense (Matarrese, 2015; Matarrese y Poiré, 2009; Ormazabal, 1999; Vecchi, 2010a, 2010b, 2016).

En todos los trabajos se determina la localización de la fuente tratada. Sin embargo, el nivel de detalle varía entre aquellas publicaciones que incorporan adicionalmente mapas ( $n=25)$, puntos georeferenciados $(n=9) \mathrm{y} / \mathrm{o}$ mapas geológicos de la zona $(n=5)$, datos que facilitan su ubicación espacial.

En la mayoría de los trabajos se explicita la manera en que se presenta la materia prima lítica. No obstante, algunos solo mencionan si se tratan de fuentes primarias o secundarias $(n=4)$, no especificando la forma en que afloran, y varios de los trabajos que incluyen más de una roca, no detallan la forma en que aparece cada una de ellas $(n=6)$. Las categorías más usadas fueron afloramiento (en un sentido amplio y confuso), rodados fluviales, clastos o nódulos individuales, filones y diques. Además, solamente 14 trabajos explicitaron el tamaño de los afloramientos en algunas de las materias primas tratadas, con categorías muy variables para su definición. Por último, 15 publicaciones mostraron imágenes de dichos afloramientos. 
En cuanto a la distribución, 20 trabajos describieron la disponibilidad de las fuentes de rocas en el paisaje. Sin embargo, ocho de ellos también lo hicieron únicamente para una o dos de las materias primas, dejando de lado las demás rocas que analizaron. Las categorías más utilizadas fueron: afloramientos abundantes, de amplia distribución, continuos, dispersos, puntuales, restringidos, aislados y escasos, incluyendo el tratamiento de la variable en distintas escalas, como regional y local. En este sentido, para el registro de disponibilidad, observamos que las categorías utilizadas fueron numerosas y que se suele confundir este criterio con el de abundancia o volumen de la materia prima de cada fuente. No obstante, se registraron casos en los que se explicitaron estos dos criterios de manera independiente. En relación con el registro de accesibilidad a las fuentes esta categoría fue explicitada en 14 trabajos. A diferencia del tratamiento heterogéneo que caracterizó al registro de disponibilidad, para abordar la accesibilidad se utilizaron solo dos criterios muy concretos: fácil y difícil acceso.

Con respecto a la determinación litológica, todos los trabajos cuentan con observaciones y descripciones macroscópicas. Solo 21 de ellos reforzaron la determinación con cortes delgados en algunas de las materias primas y tres de ellos presentan además análisis por difracción de rayos $X$. A su vez, de estos 21 trabajos, 16 incluyeron descripciones detalladas de los análisis microscópicos y sólo seis publicaron imágenes de los cortes. Aunque la mayoría de las determinaciones litológicas se hayan hecho macroscópicamente, solo cuatro trabajos indican la existencia de litotecas/muestras de mano de las rocas típicas de cada fuente.

En relación con las propiedades físicas y mecánicas de las rocas, en la mayoría de los trabajos se registró el color (n $=24$ ), con una gran variedad de tonos. Sin embargo, las descripciones resultan subjetivas debido al escaso uso de tablas de colores estandarizadas (por ejemplo, del Sistema de Munsell, 1905). Sucede algo similar con la calidad para la talla. Si bien se registra en 22 trabajos, sólo seis explicitan los criterios utilizados para su evaluación.

La cronología asociada al uso de las fuentes fue otra de las categorías relevadas. En 11 trabajos se pudo estimar el momento en que fueron explotadas: cuatro lo hicieron a partir de fechados radiocarbónicos, seis por métodos indirectos (por asociación de artefactos con otros sitios de la región con dataciones) y uno a partir de la densidad de artefactos (estiman que la fuente se usó desde hace mucho tiempo y de manera prolongada). Probablemente, los escasos datos cronológicos respondan a las características típicas de las fuentes líticas, que, en su mayoría, dificultan las asociaciones cronológicas de los artefactos (Colombo, 2013).

Finalmente, también analizamos las descripciones de los modos de explotación. En total, once trabajos abordan este tema, siendo la percusión directa, selección y recolección de nódulos sueltos o rodados y arrojado de grandes percutores/bloques, las modalidades más registradas. Si bien la mayoría de las publicaciones describen específicamente el modo de extracción usado, en algunas se utilizan categorías vagas, como, por ejemplo, "extracción de los afloramientos y bloques", "explotación de afloramiento" para referirse a los modos de explotación.

\section{Reflexiones preliminares}

Ya se dispone de una cantidad de información significativa sobre la base regional de recursos líticos (sensu Ericson, 1984). Por ello, sería importante que los diferentes grupos de investigación nos organizáramos para dar forma a una base de datos digital conjunta y de acceso abierto, que permita potenciar el uso de la información publicada. Esto se vería favorecido por una puesta en común sobre las categorías utilizadas y un esfuerzo colectivo de los distintos equipos que han reunido la información de primera mano.

A partir de esta síntesis bibliográfica y de la clasificación de gran parte de la información publicada sobre fuentes de materias primas líticas en la región pampeana bonaerense, observamos una creciente sistematicidad de las investigaciones, reflejada en el tratamiento continuo de la temática a lo largo del tiempo y en el mayor detalle con el que se las analiza en la actualidad. En términos generales, percibimos que existe un mayor desarrollo en las investigaciones sobre fuentes de materias primas líticas utilizadas para la talla frente a aquellas que fueron empleadas en actividades de picado, abradido, pulido y uso. Esta tendencia fue visibilizada por Vecchi (2010a), para las investigaciones arqueológicas en distintas temáticas.

Si bien existe gran cantidad de datos publicados, estos son muy heterogéneos. En primer lugar, existen diferentes maneras de registrar una misma categoría y, en algunos casos, no están claramente explicitados los criterios utilizados en la clasificación. En este sentido, en la mayoría de los trabajos no se expresan los criterios metodológicos que evalúan calidades de talla entre rocas. Asimismo, tampoco discernimos un consenso teórico a la hora de interpretar los tipos de sitios, es decir, fuente potencial, primaria, secundaria, si es una cantera o una canterataller. Vinculado a ello, nos preguntamos si los casos de fuentes terciarias (sensu Church, 1994) investigados en la región deberían ser registrados en la base de datos (por ejemplo, Martínez y Mackie, 2003-2004; Oliva y Pérez, 2008).

En segundo lugar, advertimos disparidades en las metodologías de relevamiento de distintas materias primas y/o fuentes al interior de una misma publicación. Por eso, en muchos casos, la cantidad de datos registrados 
Tabla 1. Materias primas identificadas con sus respectivas referencias bibliográficas.

Table 1. Raw materials identified with their respective bibliographic references.

\begin{tabular}{|c|c|}
\hline MATERIAS PRIMAS & REFERENCIAS BIBLIOGRÁFICAS \\
\hline Ortocuarcitas/cuarcitas del Grupo Sierras Bayas & $\begin{array}{l}\text { Bayón et al. 1999; Colombo 2011; Colombo 2013; Flegenheimer 1991; Flegenheimer y Bayón 2002; } \\
\text { Flegenheimer et al. 1996; Flegenheimer et al. 1999; Heider 2016; Messineo 2008; Paulides } 2005 .\end{array}$ \\
\hline Ftanita/chert o silices microcristalinos & $\begin{array}{l}\text { Barros 2009; Barros y Messineo 2004; Barros y Messineo 2006; Barros et al. 2010; Catella 2014; } \\
\text { Colombo 2013; Flegenheimer et al. 1996; Flegenheimer y Bayón 2002; Messineo 2002; Messineo } \\
\text { 2008; Messineo et al. 2004a; Paulides 2005; Valverde 2002. }\end{array}$ \\
\hline Ortocuarcitas de la Formación Balcarce & $\begin{array}{l}\text { Bayón et al. 1999; Colombo 2013; Flegenheimer et al. 1996; Matarrese 2015; Matarrese y Poiré } \\
\text { 2009; Mazzanti 1993; Vecchi 2010a; Vecchi 2010b; Vecchi 2016. }\end{array}$ \\
\hline Toba silicificada & Madrid y Salemme 1991. \\
\hline Cuarcitas pardas o "Lumb" & Matarrese 2015; Ormazabal 1999. \\
\hline Opalos & Flegenheimer 1991. \\
\hline Dolomia silicificada & $\begin{array}{l}\text { Barros 2009; Barros y Messineo 2006; Colombo 2013;Flegenheimer y Bayón 2002; Flegenheimer et } \\
\text { al. 1999; Messineo 2008; Messineo et al. 2004b; Paulides 2005. }\end{array}$ \\
\hline Hematita (pigmentos) & Flegenheimer 1991; Messineo 2008. \\
\hline $\begin{array}{l}\text { Rodados costeros (riolita, basalto, andesita, dacita, } \\
\text { silices, toba silicificada, cuarcitas, metacuarcita, } \\
\text { porfidos, gabros, vitroseros andesiticos) }\end{array}$ & $\begin{array}{l}\text { Aldazabal y Eugenio 2010; Bayón y Zavala 1997; Bonomo 2002; Bonomo 2004; Bonomo y Prates } \\
\text { 2014; Valverde 2002; Vecchi 2010a. }\end{array}$ \\
\hline Riolita & Catella 2014; Flegenheimer y Bayón 2002; Oliva y Moirano 1997; Valverde 2002. \\
\hline Ortocuarcitas/cuarcitas de Ventania & Catella 2014; Catella et al. 2010; Oliva y Barrientos 1988. \\
\hline Arenisca/arenita cuarcítica y ortocuarcítica & Aldazabal y Eugenio 2010; Catella et al. 2013; Vecchi 2010b. \\
\hline Granitos del basamento de Ventania & Catella 2014; Vecchi 2010a. \\
\hline Granitos del basamento de Tandillia & Colombo 2013; Matarrese 2015; Messineo 2008; Vecchi 2010a. \\
\hline Subarkosa & Bayón y Zavala 1997. \\
\hline Tosca & Matarrese 2015; Vecchi 2010a; Vecchi 2010b. \\
\hline Diabasa & Vecchi 2010a; Vecchi 2010b; Vecchi 2016. \\
\hline Anfibolita & Vecchi 2010a; Vecchi 2010b; Vecchi 2016. \\
\hline Andesita & Vecchi 2010a; Vecchi 2010b; Vecchi 2016. \\
\hline Tonalita & Vecchi 2010a; Vecchi 2016. \\
\hline Granodiorita & Vecchi 2010a; Vecchi 2016. \\
\hline Limonitas & Vecchi 2010a; Vecchi 2016. \\
\hline Limonitas (pigmentos) & Flegenheimer 1991. \\
\hline Metacuarcita & $\begin{array}{l}\text { Bayón et al. 1999; Bayón y Zavala 1997; Catella 2014; Flegenheimer y Bayón 2002; Matarrese 2015; } \\
\text { Matarrese y Poiré 200; Vecchi 2010a; Vecchi 2016. }\end{array}$ \\
\hline Arcillas (pigmentos) & Colombo 2013; Pedrotta 2010. \\
\hline Cuarzos & Colombo 2013. \\
\hline Cuarcitas verdes metamóficas & Matarrese 2015; Matarrese y Poiré 2009. \\
\hline Calcedonia & Catella 2014. \\
\hline Rocas silíceas opácas & Catella 2014. \\
\hline Limonita silicificada & Catella 2014. \\
\hline Areniscas calcáreas & Matarrese 2015. \\
\hline Ferrilita & Matarrese 2015. \\
\hline
\end{tabular}

por roca o lugar de aprovisionamiento no es equitativa y fácilmente comparable en un mismo trabajo, ni entre trabajos diferentes.

En tercer lugar, aún no contamos con un consenso académico en la nomenclatura de ciertas rocas. Muchas veces esta situación es producto del trabajo entre geólogos/as y arqueólogos/as y las diferencias entre las escalas de análisis utilizadas en cada disciplina. Así, por ejemplo, la ftanita también es llamada chert o sílice microcristalino dependiendo de la publicación. Una problemática similar observamos en el caso de las cuarcitas y las ortocuarcitas.

En cuarto lugar, notamos gran variabilidad en las escalas espaciales de análisis que van desde investigaciones microregionales (sensu Aschero, 1988) hasta locales o de sitios particulares (cantera o fuente). Como el tamaño de las escalas determina el grado de resolución de la unidad de análisis (el tipo de información y su detalle), necesariamente la base de datos digital deberá ser lo suficientemente flexible como para poder incluir esta variabilidad.

Finalmente, registramos una amplia diversidad de formatos de origen de la información, desde imágenes digitales e impresas, puntos GPS, mapas temáticos SIG, diarios de campo, tablas en formato Excel, muestras de rocas y cortes petrográficos. Todos ellos están aportando distintas clases de datos, diversas formas de almacenamiento, gestión y visualización de la información. Por ello, el diseño de la plataforma digital 
también deberá contemplar esta complejidad.

A pesar de la diversidad y heterogeneidad de metodologías, nomenclaturas, tipos de información y escalas de estudio, todos los trabajos relevados pudieron ser analizados bajo los criterios que empleamos. Por esto, consideramos que las categorías propuestas para esta base de datos digital fueron lo suficientemente flexibles como para incluir la información de los distintos formatos. No obstante, el uso de la herramienta digital es lo que pauta la utilidad o no de las categorías. En este sentido, creemos que la base de datos debe ser dinámica y cambiante en relación con la demanda de la comunidad de usuarios/as.

Esta información se encuentra distribuida en 37 trabajos publicados, correspondientes a 35 autores/as, con 22 lugares de trabajo en el país. Sin embargo, notamos que según el año de las publicaciones algunos/as investigadores/as cambian de lugar formal de trabajo. Como todo recorte metodológico, nuestra búsqueda dejó por fuera del análisis trabajos publicados en revistas internacionales (Mazzia et al., 2005; Porto López y Mazzanti, 2009, entre otros). No obstante, al menos uno/a de los/as autores/as de estas publicaciones está presente entre los registrados. Teniendo en cuenta esta situación y sabiendo que el número de investigadores/ as es acotado, consideramos operativo contactar directamente a las personas involucradas para el armado colectivo de la base de datos. Nos encontramos en un momento ideal para ello, ya que, actualmente la mayoría de los/as autores/as siguen aún vinculados a la disciplina.

A partir de esta experiencia consideramos que no son los datos primarios los que deberían ser digitalizados sino toda la información publicada. De esta manera quedaría asegurada la identificación de la autoría y de las referencias bibliográficas. Esto permitiría, además, que cada usuario pueda rastrear y citar debidamente los datos presentados. Asimismo, creemos que una vez reunida toda esta información de manera digital, aportaríamos a la posibilidad de construir un mapa regional de fuentes de materias primas líticas completo, preciso y estandarizado. Este ha sido un primer paso; resta ahora encontrarnos, debatir y comenzar a aunar esfuerzos para que lo que conocemos sobre las fuentes de materias primas líticas de la pampa bonaerense se encuentre en una única base de datos digital de acceso abierto.

\section{Referencias citadas}

Alberti, J., \& Fernández, V. (2015). Propuesta clasificatoria para las materias primas líticas en Patagonia (Argentina). Revista Arqueología, 21(2), 211-233.

Aldazabal, V., \& Eugenio, E. (2010). El sector costero entre Punta Rasa y Faro Querandí (Buenos Aires) como potencial fuente de recursos líticos de cazadores recolectores. En M. Berón, L. Luna, M. Bonomo, C. Montalvo, C. Aranda y M. Carrera
Aizpitarte (Eds.), Mamül Mapu: pasado y presente desde la arqueología pampeana (pp. 175-190). Ayacucho: Editorial Libros del Espinillo.

Anderson, M., \& Horgen, D. (2013). The UI-OSA Lithic Raw Material Assemblage: An Online Resource for Archaeological Studies of Debitage and Chipped Stone Tools. En O. Crandell y V. Cotiuga (Eds.), 5th Arheoinvest Symposium "Stories Written in Stones". International Symposium on Chert and other Knappable Materials (p. 73). Romania: Editura Universității.

Aschero, C. (1988). Pinturas rupestres, actividades y recursos naturales, un encuadre arqueológico. En H. Yacobaccio (Ed.), Arqueología Contemporánea Argentina (pp. 109-145). Buenos Aires: Ediciones Búsqueda.

Bamforth, D. (1992). Quarries in context: A regional perspective on lithic procurement. En J. E. Arnold (Ed.), Stone tool procurement, production and distribution in California Prehistory. Perspectives in California Archaeology, II (pp. 131-150). Los Ángeles: University of California.

Barros, M. P., \& Messineo, P. (2004). Identificación y aprovisionamiento de ftanita o chert en la cuenca Superior del Arroyo Tapalqué (Olavarría, provincia de Buenos Aires, Argentina). Estudios Atacameños, 28, 87-103.

Barros, M. P., \& Messineo, P. (2006). Abastecimiento y explotación de materias primas en el Arroyo Tapalqué (Buenos Aires, Argentina). Habitus Goilania, 4(2), 711-737.

Barros, M. P., Messineo, P., \& Colantonio, M. J. (2015). Chert quarries and workshops in the Humid Pampa sub-region: New contributions on explotation techniques and circulation through study of chaines opperatoires. Quaternary International, 375, 99-112.

Barros, M. P. (2009). Analyses des strategies d'acquisition et de production lithique dans la region pampeana, province de Buenos Aires, Argentine. (Tesis Doctoral inédita). Universite Paris Ouest Nanterre, París.

Barros, M. P., Messineo, P., Villalba, H. A., \& Colantonio, M. J. (2010). Explotación de materias primas líticas en el sector noroccidental de Tandilia y la circulación de las rocas en el centro de la subregión Pampa Húmeda. XVIII Actas de Congreso Nacional de Arqueología Argentina (p. 139). La Rioja: Universidad Nacional de La Rioja.

Bayón, C., \& Flegenheimer, N. (2004). Cambio de planes a través del tiempo para el traslado de roca en la Pampa Bonaerense. Estudios atacameños, 28, 59-70.

Bayón, C., \& Zavala, C. (1997). Coastal sites in southern Buenos Aires: a review of piedras quebradas. En J. Rabassa y $\mathrm{M}$. Salemme (Eds.), Quaternary Internacional of South America and Antartic Peninsula 10 (pp. 229-253). Rótterdam: A.A. Balkerna Publisshers. 
Bayón, C., Flegenheimer, N., \& Pupio, A. (2006). Planes sociales para el abastecimiento y traslado de roca en la Pampa Bonaerense en el Holoceno temprano y tardío. Relaciones de la Sociedad Argentina de Antropología, XXXI, 19-45.

Bayón, C., Flegenheimer, N., Valente, M., \& Pupio, A. (1999). Dime cómo eres y te diré de dónde vienes: procedencia de rocas cuarcíticas en la Región Pampeana. Relaciones de la Sociedad Argentina de Antropología, XXIV, 187-217.

Bellelli, C. (1988). Recursos minerales: su estrategia de aprovisionamiento en los niveles tempranos de Campo Moncada 2 (Valle de Piedra Parada, río Chubut). En H. Yacobaccio (Ed.), Arqueología contemporánea argentina. Actualidad y perspectivas (pp. 147-176). Buenos Aires: Búsqueda.

Berón, M. (2006). Base regional de recursos minerales en el occidente pampeano. Procedencia y estrategias de aprovisionamiento. Relaciones de la Sociedad Argentina de Antropología, XXXI, 47-88.

Binford, L. (1962). Archaeology as Anthropology. American Antiquity, 28(2), 217-225.

Bonomo, M., \& Prates, L. (2014). La explotación de depósitos secundarios de rodados en el curso medio del río Negro y el litoral marítimo pampeano. En P. Escola y S. Hocsman (Eds.), Artefactos Líticos, Movilidad y Funcionalidad de Sitios en Sudamérica. Problemas y Perspectivas (pp. 77-92). Oxford: British Archaeological Reports (BAR) International Series.

Bonomo, M. (2002). Distribución espacial y tecnología en el litoral marítimo Bonaerense. En D. Mazzanti, M. Berón y F. Oliva (Eds.), Del mar a los salitrales. Diez mil años de Historia Pampeana en el Umbral del Tercer Milenio (pp. 185-204). Mar del Plata: Universidad Nacional de Mar del Plata.

Bonomo, M. (2004). Ocupaciones Humanas en el Litoral Marítimo Pampeano: Un Enfoque Arqueológico. (Tesis Doctoral inédita), Universidad Nacional de La Plata, Argentina.

Borrel, M., Fuente, M. V., \& González, C. (2015). Una propuesta metodológica de relevamiento para iniciar proyectos de digitalización y preservación. En L. Cantamutto, G. del Río Riande y G. Striker (Eds.), Actas de las I Jornadas Nacionales de Humanidades Digitales (pp. 69-84). Buenos Aires: Editorial de la Facultad de Filosofía y Letras, UBA.

Cantamutto, L., \& Delfa, C. V. (2015). Repositorio colaborativo de comunicaciones digitales: aproximación a un corpus para el español. En L. Cantamutto, G. del Río Riande y G. Striker (Eds.), Actas de las I Jornadas Nacionales de Humanidades Digitales (pp. 107-129). Buenos Aires: Editorial de la Facultad de Filosofía y Letras, UBA.

Catella, L. (2014). Movilidad y Utilización del Ambiente en Poblaciones Cazadoras-Recolectoras del Sur de la Región Pampeana: La cuenca del Arroyo Chasicó como Caso de
Estudio. (Tesis Doctoral inédita). Universidad Nacional de La Plata, Argentina.

Catella, L., Manassero, M., Moirano, J., \& Oliva, F. (2013). Nuevos aportes al estudio del aprovisionamiento de cuarcitas en la Región Pampeana, Argentina. Cuadernos del INAPL, Series Especiales I(2), 200-215.

Catella, L., Moirano, J., \& Oliva, F. (2010). Disponibilidad de materias primas líticas y su importancia para el análisis del uso del espacio y la organización de la tecnología en sociedades cazadoras recolectoras. En M. Berón, L. Luna, M. Bonomo, C. Montalvo, C. Aranda y M. Carrera Aizpitarte (Eds.), Mamul Mapu: pasado y presente desde la arqueología pampeana (pp. 215-230). Ayacucho: Editorial Libro del Espinillo.

Church, T. (1994). Lithic resource studies: a sourcebook for archaeologists. Tulsa: Department of Anthropology, University of Tulsa.

Colombo, M. (2011). El área de abastecimiento de las ortocuarcitas del Grupo Sierras Bayas y las posibles técnicas para su obtención entre los cazadores-recolectores pampeanos. Intersecciones en Antropología, 12, 231-243.

Colombo, M. (2013). Los cazadores recolectores pampeanos y sus rocas. La obtención de materias primas líticas vista desde las canteras arqueológicas del centro de Tandilia. (Tesis Doctoral inédita). Universidad Nacional de La Plata, Argentina.

Crandell, O. (2009). Romanian Lithotheque Project: Knappable stone resources in the Mures Valley, Romania. Studia Universitatis Babes-Bolyai, Geologia, Special Issue, MAEGS $\mathrm{XVI}, 79-80$

Ditchfield, K., \& Ward, I. (2019). Local lithic landscapes and local source complexity: Developing a new database for geological sourcing of archaeological stone artefacts in North-Western Australia. Journal of Archaeological Science, XXIV, 539-555.

Driscoll, K., Burke, A., \& Warren, G. (2016). Introducing LIR (Lithotheque Ireland), a reference collection of flaked stone tool raw materials from Ireland. Journal of Lithic Studies, III(2). https://doi.org/10.2218/jls.v3i2.1444.

Ericson, J. (1984). Toward the analysis of lithic production systems. En J. Ericson y B. Purdy (Eds.), Prehistoric Quarries and Lithic Production (pp 1-10). Cambridge: Cambridge University.

Escola, P. (2003). Disponibilidad de recursos líticos y fuentes de aprovisionamiento en un sector de la Puna Meridional. Mundo de Antes, 3, 65-86

Fernández, V., \& Alberti, J. (2013). Lithotheques, Interdiscipline and Common Language Among Archaeologists and Geologists: An example from Patagonia (Argentina). En O. Crandell y V. Cotiuga (Eds.), 5th Arheoinvest Symposium "Stories Written in Stones". International Symposium on Chert and other 
Knappable Materials (p. 73). Romania: Editura Universității.

Flegenheimer, N., \& Bayón, C. (2002). ¿Cómo, cuándo y dónde? Estrategias de abastecimiento lítico en La Pampa Bonaerense. En D. Mazzanti, M. Berón y F. Oliva (Eds.), Del Mar de los Salitrales. Diez mil Años de Historia Pampeana en el Umbral del Tercer Milenio (pp. 231-241). Mar del Plata: Universidad Nacional de Mar del Plata.

Flegenheimer, N., \& Bellelli, C. (2007). La arqueología y las piedras. Un recorrido por los estudios líticos en Argentina. Relaciones de la Sociedad Argentina de Antropología, XXXII, 141-168.

Flegenheimer, N. (1991). La Liebre un sitio de cantera-taller. Boletín del Centro, II, 58-64.

Flegenheimer, N., Kain, S., Zárate, M., \& Barna, A. (1996). Aprovisionamiento de cuarcitas en Tandilia, las canteras del Arroyo Diamante. Revista Arqueología, VI, 117-137.

Flegenheimer, N., Zárate, M., \& Valente, M. (1999). El área de canteras Arroyo Diamante, Barker, Sierras de Tandil. Actas del XII Congreso Nacional de Arqueología Argentina (pp. 134138). La Plata.

Harvey, R. (2007). Appraisal and Selection. En S. Ross y M. Day (Eds.), Curation Reference Manual. Recuperado de http:// www.dcc.ac.uk/resource/curation-manual/chapters/appraisalandselection

Heider, G. (2016). Un aporte a la discusión sobre las ortocuarcitas del Grupo Sierras Bayas ¿El sur de Córdoba como una frontera? Intersecciones en Antropología, 17, 303-313.

Izeta, A., \& Cattáneo, R. (2018). ¿Es posible una arqueología digital en Argentina? Un acercamiento desde la práctica. En G. del Rio Riande, G. Calarco, G. Striker y R. De León (Eds.), Humanidades Digitales: Construcciones locales en contextos globales: Actas del I Congreso Internacional de la Asociación Argentina de Humanidades Digitales. Buenos Aires: Editorial de la Facultad de Filosofía y Letras, UBA. Recuperado de https:// www.aacademica.org/aahd.congreso/15.pdf

Lee, C. A., \& Tibbo, H. R. (2007). Digital Curation and Trusted Repositories: Steps Toward Success. Journal of Digital Information, VIII (2). Recuperado de https://journals.tdl.org/ jodi/index.php/jodi/article/view/229/183

Madrid, P., \& Salemme, M. (1991). La ocupación Tardía del sitio 1 de la Laguna Tres Reyes, partido de Adolfo Gonzales Chaves provincia de Bs. As. Boletín del Centro, III, 165-179.

Martínez, G., \& Mackie, Q. (2003-2004). Late Holocene human occupation of the Quequén Grande River Valley botton: Settlement systems and an example of a built environment in the Argentine Pampas. Before Farming, 1, 1:127.
Matarrese, A. (2015). Tecnología lítica entre los cazadoresrecolectores pampeanos: los artefactos formatizados por picado y abrasión y modificados por uso en el Área Interserrana Bonaerense. (Tesis Doctoral inédita), Universidad Nacional de La Plata, Argentina

Matarrese, A. B., \& Poiré, D. G. (2009). Rocas para moler: análisis de procedencia de materias primas líticas para artefactos de molienda (Área Interserrana Bonaerense). Intersecciones en Antropología, 10,121-140.

Mazzanti, D. (1993). Investigaciones arqueológicas en el sitio Cueva Tixi (provincia de Buenos Aires). Etnia, XXXVIII, 125-163.

Mazzanti, D. (2006). La constitución de los territorios sociales durante el Holoceno tardío. El caso de las Sierras de Tandilia, Argentina. Relaciones de la Sociedad Argentina de Antropología, XXXI, 277-300.

Mazzia, N., Flegenheimer, N., \& Poiré, D. (2005). Not only flaked artifacts in early Pampean lithic assemblages (Argentina). Current Research in the Pleistocene, 22, 25-27.

Messineo, P., \& Barros, M. P. (2015). Lithic raw materials and modes of exploitation in quarries and workshops from the center of the Pampean grassland of Argentina. Lithic Technology, XXXX (1), 3-20.

Messineo, P. (2002). Primeros resultados arqueológicos en la cuenca del Arroyo Tapalqué (pdo. de Olavarría, Pcia. de Buenos Aires). En M. Mazzanti, D., M. Berón y F. Oliva (Eds.), Del mar a los salitrales. Diez mil años de Historia Pampeana en el Umbral del Tercer Milenio (pp. 301-309). Mar del Plata: Universidad Nacional de Mar del Plata.

Messineo, P. (2008). Investigaciones arqueológicas en la cuenca superior del Arroyo Tapalqué (partidos de Olavarría y Benito Juárez, provincia de Buenos Aires). (Tesis Doctoral inédita). Universidad Nacional de La Plata, Argentina.

Messineo, P., Barros, M. P., Pérez, J., \& Piccione, G. (2004a). Cerro Tres lomas 1: una cantera-taller de dolomía silicificada en las sierras de Olavarría (Provincia de Buenos Aires). Resúmenes del XV Congreso Nacional de Arqueología Argentina (pp. 350). Río Cuarto.

Messineo, P., Barros, M. P., Poiré, M. P., \& Peral, L. G. (2004b). Características litológicas de los niveles de chert o ftanitas en las Sierras Bayas (partido de Olavarría, provincia de Buenos Aires). En G. Martínez, M. Gutiérrez, R. Curtoni, M. Berón y P. Madrid (Eds.), Aproximaciones contemporáneas a la arqueología pampeana. Perspectivas Teóricas, Metodológicas y casos de estudio (pp. 305-317). Olavarría.

Munsell, A. (1905). A Color Notation. Boston: Editorial G. H. Ellis Co.

Nami, H. (1992). El subsistema tecnológico de la confección 
de instrumentos líticos y la explotación de los recursos del ambiente: una nueva vía de aproximación. Shincal, II, 33-53.

Oliva, F., \& Barrientos, G. (1988). Laguna de Puan: un potencial sitio de aprovisionamiento de materia prima lítica. Libro de resúmenes del IX Congreso Nacional de Arqueología Argentina (pp. 46-47). Buenos Aires.

Oliva, F., \& Moirano, J. (1997). Primer informe sobre aprovisionamiento primario de riolita en Sierra de la ventana (Provincia de Buenos Aires, Argentina). En M. Berón G. Politis (Eds.), Arqueología pampeana en la década de los '90 (pp. 137-145). Museo de Historia Natural de San Rafael, Mendoza: INCUAPA-FACSO, UNCPBA.

Oliva, F., \& Pérez, I. (2008). Análisis cuantitativo de "reservorios" o "caches" de artefactos y materias primas líticas de sitios del borde occidental de la Pampa Húmeda. In A. Austral \& M. Tamagnini (Comps.), Problemáticas de la arqueología Contemporánea, 2 (pp. 345-354). Rio Cuarto: Universidad Nacional de Rio Cuarto.

Ormazabal, P. (1999). Lumb: un sitio de aprovisionamiento de materia prima lítica para elementos de molienda. Actas del XII Congreso Nacional de Arqueología (pp. 156-164).

Ortega, D., Roqué, C., \& Terradas, X. (2017). Disponibilidad de rocas silíceas en el Noreste Peninsular: Resultados del Proyecto LITOCAT. CPAG, XXVI, $245-282$.

Paulides, L. (2005). Formando Rocas. (Tesis de licenciatura inédita) Facultad de Filosofía y Letras, Universidad Nacional de Buenos Aires, Argentina.

Pedrotta, V. (2010). Avances en el estudio de pigmentos minerales: el caso de las sierras de Curicó (Tandilia, región pampeana, Argentina). Cazadores-recolectores del Cono Sur, IV, 175-186.

Pluss, R., \& Leff, L. (2013, Septiembre). Plataforma Interactiva de Investigación para las Ciencias Sociales. Jornadas Argentinas de Informática, 42 JAIIO, Universidad Nacional de Córdoba, Córdoba.

Pluss, R., \& Leff, L. (2016, Noviembre-Diciembre). Lineamientos para la gestión de datos científicos nacionales: La experiencia de la iniciativa PLIICS en Argentina. Producción y uso de conocimiento - Relaciones entre investigación científica y cambio tecnológico. Segundo Congreso Argentino de Estudios Sociales de la Ciencia y la Tecnología (CAESCYT), Centro de Estudios en Ciencia, Tecnología, Cultura y Desarrollo (CITECDE) de la UNRN, San Carlos de Bariloche, Argentina.
Porto López, J., \& Mazzanti, D. (2009). Pigmentos minerales arqueológicos y sus fuentes de aprovisionamiento del sudeste bonaerense: análisis arqueométrico comparativo. Arqueometría Latinoamericana, I, 215-220.

Sánchez de La Torre, M., Rey, M., Rodríguez, N., Casado, A., Medina, B., \& Mangado, X. (2014). The LithicUB Project: A virtual lithotheque of siliceous Rocks at the University of Barcelona. Journal of Lithic Studies, I (1), 281-292.

Soto, M., Gomez De Soler, B., \& Vallverdú, J. (2017). LithIPHES: A lithic Reference Collection for the NE Iberian Peninsula Prehistory. En J. Alberti, K. Borrazzo, S. Buscaglia, A. Castro Esnal, A. Elías y N. Franco (Eds.), 11th International Symposium on Knappable Materials. "From Toolstone to Stone Tools", (p. 205). Buenos Aires, Argentina: IMHICIHU.

Theriault, C. (2013). A Proposal for the Creation of a Lithotheque In The Province Of New Brunswick, Canada. En O. Crandell y V. Cotiuga (Eds.), 5th Arheoinvest Symposium "Stories Written in Stones". International Symposium on Chert and other Knappable Materials (p. 73). Romania: Editura Universității.

Valverde, F. (2002). Variabilidad de los recursos líticos en dos sitios paleoindios de las Sierras de Tandillia Oriental, Provincia de Buenos Aires. En D. Mazzanti, M. Berón y F. Oliva (Eds.), Del mar a los salitrales. Diez mil años de Historia Pampeana en el Umbral del Tercer Milenio (pp. 279-288). Mar del Plata: Universidad Nacional de Mar del Plata.

Vecchi, R. (2010a). Bolas de boleadora en los grupos cazadores recolectores de la pampa bonaerense. (Tesis Doctoral inédita). Universidad de Buenos Aires, Argentina.

Vecchi, R. (2010b). Materias primas de boleadoras en el Área Interserrana Costera: Localidad Arqueológica El Guanaco. En M. Berón, L. Luna, M. Bonomo, C. Montalvo, C. Aranda y M. Carrera Aizpitarte (Eds.), Mamül Mapu: pasado y presente desde la arqueología pampeana (pp. 175-190). Ayacucho: Editorial Libros del Espinillo.

Vecchi, R. (2016). Materias primas líticas de bolas de boleadora del sector bonaerense de la Región Pampeana. Relaciones de la Sociedad Argentina de Antropología, XLI (1): 191-215.

Werra, D., Sokolska-Majchrzak, A., \& Osiadacz, M. (2017). Polish Lithoteka Project: Siliceous Rock in East-Central Europe. En J. Alberti, K.Borrazzo, S. Buscaglia, A. Castro Esnal, A. Elías y N. Franco (Eds.), 11th International Symposium on Knappable Materials. "From Toolstone to Stone Tools", (p. 185). Buenos Aires, Argentina: IMHICIHU. 